\title{
EFEKTIVITAS KERASIONALAN PEMBERIAN ANTIDIABETIK PENGOBATAN ORAL PASIEN DIABETES MELLITUS PADA USIA 30-50 TAHUN TIPE 2 DI RAWAT INAP PENYAKIT DALAM RSUD DELI SERDANG LUBUK PAKAM TAHUN 2020
}

\section{${ }^{1}$ Loraetta Brety Sebayang, ${ }^{2}$ Romauli Anna Teresia Marbun ${ }^{3}$ Dewi Kartika}

\author{
Institut Kesehatan Medistra Lubuk Pakam \\ Jalan Sudirman No.38 Lubuk Pakam, Kab. Deli Serdang, Sumatera Utara \\ 20512 \\ e-mail : loraettabretysebayang@gmail.com \\ DOI $10.35451 /$ jfm.v3i2.582
}

\begin{abstract}
Background: Diabetes Mellitus is a chronic condition, which occurs because the body cannot produce insulin, normally or insulin cannot work effectively. Objective: To determine the effectiveness of the rational administration of antidiabetic, oral treatment of diabetes mellitus patients at the age of 30-50 years type 2 in Deli Serdang Hospital, lubuk pakam in 2020. Method: This study is a non-experimental type of research using descriptive methods. Results: Shows that from 72 samples of Type II Diabetes Mellitus patients at Deli Serdang General Hospital, April-July Period 2020. With the number $(52.8 \%)$ of male sex patients and the number (47.2\%) of type patients female genitalia and antidiabetic drugs most widely used by patients, in the period of April-July 2020, namely (20.8\%) glycionion + metformin and $(20.8 \%)$ insulin drugs. the use of DM drugs with the right rational indication (65.3\%), Rational with the right medicine $(100 \%)$, rational with the right dosage $(100 \%)$, the right rational patient (100\%) and the rational way of administration (100: \%).

Conclusion: Evaluation of drug use is a structured quality assurance process that is carried out continuously to ensure that the drugs used are appropriate, safe, and efficient.
\end{abstract}

Keywords: Effectiveness of drug rationality, diabetes mellitus, antidiabetic

\section{PENDAHULUAN}

Menurut Amerika Diabetes Association (ADA) tahun,2010. Diabetes Melitus (DM) adalah penyakit metabolik dengan karakteristik hiperglikemia yang terjadi karena kelainan sekresi insulin, kerja insulin atau kedua-duanya.

Diabetes Mellitus merupakan kondisi kronik yang terjadi karena tubuh tidak dapat memproduksi insulin secara nornal atau insulin tidak dapat memproduksi insulin secara normal atau insulin tidak dapat bekerja secara efektif. Insulin merupakan hormon yang dihasilkan oleh pankreas dan berfungsi untuk memasukkan glukosa yang diperoleh dari makanan ke dalam sel yang selanjutnya akan di ubah menjadi energi yang dibutuhkan oleh otot dan jaringan untuk bekerja sesuai fungsinya. Seseorang yang terkena Diabetes Melitus tidak dapat menggunakan glukosa secara normal dan glukosa akan tetapi pada sirkulasi darah yang akan merusak jaringan. Kerusakan ini terjadi berlangsung kronis akan menyebabkan terjadinya komplikasi, seperti penyakit 
kardiovaskular, nefropati, retinopati, neuropati dan ulkus pedis (International Diabetes Federation, 2016)

Tingginya angka kejadian serta pentingnya penanganan secara tepat terhadap penyakit Diabetes Melitus dan komplikasi yang ditimbulkannya, maka terapi Diabetes Melitus harus dilakukan secara rasional. Kerasionalan pengobatan terdiri atas ketepatan terapi yang dipengaruhi proses diagnosis, pemilihan terapi, pemberian terapi, serta evaluasi terapi. Evaluasi penggunaan obat merupakan suatu proses jaminan mutu yang terstruktur dan dilakukan secara terus menerus untuk menjamin agar obat-obat yang digunakan tepat, aman dan efisien (Kumolosari, 2017).

Menurut World Health Organization/ WHO (2012) bahwa jumlah klien dengan Diabetes Melitus di dunia mencapai 347 juta orang dan lebih dari $80 \%$ kematian. Pada tahun 2020 diperkirakan 178 juta penduduk indonesia berusia diatas 20 tahun dengan asumsi prevalensi Diabetes Melitus sebesar 4,6 akan didapatkan 8,2 juta klien yang menderita Diabetes Melitus. Dari hasil penelitian yang dilakukan pada seluruh propinsi yang ada di indonesia menunjukkan bahwa prevalensi nasional untuk toleransi glukosa tertanggu ( TGT) adalah sebesar $10,25 \%$ dan untuk Diabetes Melitus adalah sebesar 5,7\% (Balitbang Depkes RI, 2008).

Pasien seharusnya mendapatkan pengobatan yang rasional juga dengan biaya yang paling rendah (WHO, 2012). Penyakit Diabetes Melitus bisa menyebabkan komplikasi penyakit yang membahayakan jiwa maupun mempengaruhi kualitas hidup seseorang. Pada tahun 2000, jumlah penderita Diabetes Melitus mencapai kira-kira 150 juta dan diperkirakan pada tahun 2025 akan ada 300 juta orang dewasa dengan Diabetes Melitus (Poretsky, 2016).

Indonesia berada diperingkat keempat jumlah penyandang Diabetes Melitus di dunia setelah Amerika Serikat, India dan Cina (Hans, 2008). Berdasarkan hasil Riset Kesehatan Dasar (Riskesdas) 2007, angka prevalensi Diabetes Melitus tertinggi terdapat di provinsi Kalimantan Barat dan Maluku Utara (masing-masing 11,1 persen), diikuti Riau (10,4 persen) dan NAD ( 8,5 persen). Prevalensi Diabetes Melitus terendah ada di propinsi Papua (1,7 persan), diikuti NNT ( 1,8 persen). Prevalensi Diabetes di Sulawesi Utara berdasarkan kesehatan propinsi Sulawesi Utara tahun 2008 di dapatkan angka lebih tinggi provinsi propinsi Sulawesi Utara $(1,6 \%)$ dari pada angka nasional $(1,0 \%)$. Penyakit ini tersebar di seluruh Utara dengan prevalensi tertinggi di kota manado (Suyono, 2016).

International Diabetes federation (IDF) menyebutkan bahwa prevalensi Diabetes Melitus di dunia adalah 1,9\% dan telah menjadikan Diabetes Melitus sebagai penyebab kematian urusan ke tujuh didunia sedangkan tahun 2012 angka kejadian diabetes melitus didunia adalah sebanyak 371 juta jiwa dimana proporsi kejadian diabetes melitus tipe 2 adalah $95 \%$ dari populasi dunia yang menderita diabetes mellitus.

Diabetes Melitus jika tidak ditangani dengan baik akan mengakibatkan timbulnya komplikasi pada berbagai organ tubuh seperti mata, jantung, ginjal, pembuluh darah kaki, syaraf dan lain-lain. Penderita Diabetes Melitus dibandingkan dengan penderita non Diabetes Melitus mempunyai kecenderungan 25 kali terjadi buta, 2 kali terjadi penyakit jantung koroner, 7 kali terjadi gagal ginjal kronik, dan 5 kali menderita ulkus diabetika. Komplikasi menahun Diabetes Melitus di Indonesia terdiri atas neuropati $60 \%$, penyakit 
jantung koroner $20,5 \%$, ulkus diabetika $15 \%$, retinopati $10 \%$, dan nefropati $7,1 \%$.

Berdasarkan survei pendahuluan yang telah dilakukan oleh peneliti di Rumah Sakit Umum Daerah ( RSUD ) Deli Sedang Lubuk Pakam bahwasannya pada tahun 2019 terdapat 250 pasien diabetes mellitus tipe 2 pada dewasa, obat oral yang digunakan pada pasien yang mengalami penyakit diabetes mellitus tipe 2 di Rumah Sakit Umum Daerah Deli Serdang Lubuk Pakam. Hal inilah yang melatar belakangi penelitian untuk melakukan penelitian tentang evaluasi kerasionalan pemberian antidiabetik oral pada pengobatan pasien diabetes mellitus tipe 2 di bangsal Rumah sakit Deli Serdang lubuk Pakam.

\section{METODE}

Jenis penelitian ini merupakan jenis penelitian non eksperimental dengan menggunakan metode deskriptif, yaitu penelitian yang bertujuan untuk mendapatkan gambaran atau deskripsi tentang suatu keadaan secara objektif, pengambilan data dilakukan secara retrospektif yaitu suatu penelitian yang mengkaji informasi atau mengambil data yang telah lalu dengan menggunakan data sekunder (Benardi, 2015).

Populasi yang digunakan dalam penelitian ini adalah seluruh pasien diabetes melitus tipe 2 yang tercatat dalam rekam medik di ruang rawat inap di Rumah Sakit Umum Daerah Deli Serdang Lubuk Pakam pada periode Oktober 2019 s/d maret 2020 sebanyak 250 orang .

Sampel dalam penelitian ini adalah sebagian dari populasi yang memenuhi kriterial inklusi. Teknik pengambilan sampel yang di gunakan adalah sampel di ambil secara acak sederhana (simple random sampling). Dimana sampel yang di ambil harus memenuhi Kriterial inklusi dan dihitung berdasarkan rumus sampel yang di ambil minimal slovin. Dengan jumlah populasi 250 dan batas toleransi kesalahan $10 \%(0,1)$ maka diperoleh besar sampel minimal 72 pasien

\section{HASIL DAN PEMBAHASAN}

Tabel 1. Distribusi karakteristik responden dari rekam medik berdasarkan Jenis Kelamin

\begin{tabular}{lcc}
\hline JENIS KELAMIN & F & \% \\
\hline Laki Laki & 38 & 52,8 \\
Perempuan & 34 & 47,2 \\
\hline Total & 72 & 100,0
\end{tabular}

Tabel 2. Distribusi Frekuensi berdasarkan Jadwal Kontrol

\begin{tabular}{l|l|l}
\hline Jadwal Kontrol & F & \% \\
\hline Sebulan 1 kali & 33 & 45,8 \\
\hline Sebulan 2 kali & 29 & 40,3 \\
\hline Tiga bulan 1 kali & 10 & 13,9 \\
\hline Total & 72 & 100,0 \\
\hline
\end{tabular}

Tabel 3. Distribusi Frekuensi berdasarkan Pendidikan

\begin{tabular}{lcc}
\hline PENDIDIKAN & F & $\mathbf{\%}$ \\
\hline Tidak Sekolah & 15 & 20,8 \\
SD & 4 & 5,6 \\
SMP & 10 & 13,9 \\
SMA & 24 & 33,3 \\
Diploma & 8 & 11,1 \\
Sarjana (S1) & 11 & 15,3 \\
\hline Total & 72 & 100,0 \\
\hline
\end{tabular}


Jurnal Farmasi, e-ISSN: 2655-0814

Vol. 3 No.2 Edisi November 2021-April 2021

http://ejournal.medistra.ac.id/index.php/JFM

Received: 14 Januari 2021 :: Accepted: 28 April 2021 :: Published: 30 April 2021

Tabel 4. Distribusi Frekuensi berdasarkan Pekerjaan

\begin{tabular}{lcc}
\hline PEKERJAAN & F & \% \\
\hline PNS/TNI/POLRI & 10 & 13,9 \\
Karyawan & 17 & 23,9 \\
Swasta/BUMN & & \\
Wiraswasta/ & 23 & 31,9 \\
$\begin{array}{l}\text { Pedagang } \\
\text { Petani }\end{array}$ & 22 & 30,6 \\
\hline Total & 72 & 100,0 \\
\hline
\end{tabular}

Tabel 5. Distribusi Frekuensi berdasarkan Penghasilan

\begin{tabular}{lcc}
\hline PENGHASILAN & F & $\mathbf{\%}$ \\
\hline$<1.00 .0000$ & 23 & 31,9 \\
$1.000 .000-2.000 .000$ & 24 & 33,3 \\
$2.000 .000-3.000 .000$ & 13 & 18,1 \\
$>3.000 .000$ & 12 & 16,7 \\
\hline Total & 72 & 100,0 \\
\hline
\end{tabular}

Tabel 6. Berdasarkan hasil analisis deskriftif tepat indikasi, tepat Obat, tepat pasien dan tepat dosis terhadap pemberian obat antidiabetik pada pasien diabetes melitus tipe II

\begin{tabular}{|c|c|c|c|c|c|}
\hline \multicolumn{6}{|c|}{ Descriptive Statistics } \\
\hline & $\mathrm{N}$ & $\begin{array}{l}\text { Mini } \\
\text { mum }\end{array}$ & $\begin{array}{l}\text { Maxim } \\
\text { um }\end{array}$ & $\begin{array}{c}\text { Mea } \\
\mathrm{n}\end{array}$ & $\begin{array}{c}\text { Std. } \\
\text { Deviation }\end{array}$ \\
\hline $\begin{array}{l}\text { Tepat } \\
\text { Indikasi }\end{array}$ & $\begin{array}{l}7 \\
2\end{array}$ & 1 & 2 & 1.35 & .479 \\
\hline $\begin{array}{l}\text { Tepat } \\
\text { Obat }\end{array}$ & $\begin{array}{l}7 \\
2\end{array}$ & 1 & 1 & 1.00 & .000 \\
\hline $\begin{array}{l}\text { Tepat } \\
\text { Pasien }\end{array}$ & $\begin{array}{l}7 \\
2\end{array}$ & 1 & 1 & 1.00 & .000 \\
\hline $\begin{array}{l}\text { Tepat } \\
\text { Dosis }\end{array}$ & $\begin{array}{l}7 \\
2\end{array}$ & 1 & 2 & 1.36 & .484 \\
\hline $\begin{array}{l}\text { Valid N } \\
\text { (listwise } \\
\text { ) }\end{array}$ & $\begin{array}{l}7 \\
2\end{array}$ & & & & \\
\hline
\end{tabular}

Tabel 7. Berdasarkan hasil Frekuensi jenis obat terhadap pemberian obat antidiabetik pada pasien diabetes melitus tipe II

\begin{tabular}{|c|c|c|c|c|c|}
\hline & & Frequency & Percent & Valid Percent & $\begin{array}{c}\text { Cumulative } \\
\text { Percent }\end{array}$ \\
\hline Valid & Glikuidion+Metformin & 15 & 20.8 & 20.8 & 20.8 \\
\hline & Glikuidon & 11 & 15.3 & 15.3 & 36.1 \\
\hline & Glimepirid & 15 & 20.8 & 20.8 & 56.9 \\
\hline & Insulin & 15 & 20.8 & 20.8 & 77.8 \\
\hline & Metfomin+Insulin & 12 & 16.7 & 16.7 & 94.4 \\
\hline & Metformin & 4 & 5.6 & 5.6 & 100.0 \\
\hline & Total & 72 & 100.0 & 100.0 & \\
\hline
\end{tabular}

\section{PEMBAHASAN}

\begin{tabular}{lll}
\multicolumn{1}{c}{ Berdasarkan } & hasil & diatas \\
menunjukkan & bahwa & dari 72 \\
responden & dalam & pemberian
\end{tabular} antidiabetic oral responden yang diberikan ada 63 orang $(63,7 \%)$ yang tidak diberikan ada 9 orang $(12,5 \%)$ dari hasil diatas disimpulkan bahwa responden yang paling banyak yakni responden yang diberikan ada 63 orang $(87,5 \%)$.

Berdasarkan data hasil penelitian diatas menunjukan bahwa dari 72 responden yang pemberian antidiabetic oral Tepat indikasi Tepat ada 47 orang $(65,3 \%)$ tidak tepat ada 25 orang $(34,7 \%)$ pemberian obat antidiabetic oral tepat obat tepat ada 72 orang $(100,0 \%)$ dan tepat pasien Tepat ada 72 orang $(100,0 \%)$ tepat dosis tepat ada 46 orang $(63,9 \%)$, Tidak Tepat ada 
36 orang $(36,1 \%)$ dengan demikian jumlah yang paling banyak dari responden tepat indikasi yakni Tepat ada 47 orang $(65,3 \%)$, Tepat Obat ada 72 orang $(100,0 \%)$, Tepat Pasien ada 72 orang $(100,0 \%)$ dan tepat Dosis ada 46 orang $(63,9 \%)$.

\section{KESIMPULAN}

Kerasionalan pemberian antidiabetik oral pada pasien penyakit diabetes melitus pada usia 30-50 tahun tipe 2 berdasarkan jenis oral di Rumah Sakit Umum Daerah Deli Serdang lubuk Pakam. Hasil penelitian menunjukan bahwa bahwa kebanyakan responden yang diberikan obat dengan jenis obat Insulin ada 14 orang $(19,4 \%)$ dan pasien yang tidak diberikan Metrofin.

Penggunaan pemberian antidiabetik oral pada pasien penyakit diabetes mellitus pada usia 30-50 tahun tipe 2 berdasarkan tepat pasien, tepat indikasi , tepat obat, tepat dosis di Rumah Sakit Umum Daerah Deli Serdang Lubuk Pakam. Hasil penelitian tabel 4.2.2 diatas menunjukan bahwa dari 72 responden yang pemberian antidiabetic oral Tepat indikasi Tepat ada 47 orang $(65,3 \%)$ tidak tepat ada 25 orang $(34,7 \%)$ pemberian obat antidiabetic oral tepat obat tepat ada 72 orang $(100,0 \%)$ dan tepat pasien Tepat ada 72 orang $(100,0 \%)$ tepat dosis tepat ada 46 orang $(63,9 \%)$, Tidak Tepat ada 36 orang $(36,1 \%)$ dengan demikian jumlah yang paling banyak dari responden tepat indikasi yakni Tepat ada 47 orang $(65,3 \%)$,Tepat Obat ada 72 orang $(100,0 \%)$, Tepat Pasien ada 72 orang $(100,0 \%)$ dan tepat Dosis ada 46 orang $(63,9 \%)$.

\section{DAFTAR PUSTAKA}

[AACE]. 2009, Statement by an American Association of Clinical Endocrinologists Consensus Panel On Type 2 Diabetes
Mellitus : An Algoritm for Glycemic Control, Vol 15 No 6, American Association of Clinical Endocrinologists Medical.

[ADA] American Diabetes Association 2015. Diagnosis and Classification of DM. Diabetes Care, vol 27. Available from: http:// care. diabetesjournals. org/ content 27/suppl_1/s5.full.pdf+html [20 Agustusr 2016].

[ADA] American Diabetes Asoociation. 2015. Standards of Medical Care In Diabetes 2014, Vol 37 (suppl 1). American Diabetes Asoociation. Hal. 27

[Anonim], 2015, Dasar-dasar Pemeriksaan Mikrobiologi, 15121, Bagian Mikrobiologi, Fakultas Kedokteran, Universitas Gadjah Mada, Yogyakarta

[Anonim], 2015 a, Pharmaceutical Care untuk Penyakit Diabetes Mellitus, 8- 76, Direktorat Bina Farmasi Komunitas dan Klinik Direktorat Jenderal Bina Kefarmasian dan Alat Kesehatan Departemen Kesehatan RI November 2009.

[Anonim], 2015, Pedoman Penggunaan Obat Bebas dan Obat Bebas terbatas, Direktorat Bina Farmasis Komunitas dan Klinik Direktorat Jendral Bina Kefarmasian dan Alat Kesehatan Depkes RI.

Arnold Hongdiyanto., Paulina V. Y. Yamlean., dan Hamidah Sri Supriati (2015). Evaluasi Kerasionalan Pengobatan Diabetes Melitus Tipe 2 Pada Pasien Rawat Inap Di Rsup. Dr. R. D. Kandou Manado Tahun 2013. Jurnal IImiah Farmasi UNSRAT Vol. 3 No. 2

Arifin, I., Prasetyaningrum, E., \& Andayani, T.M. (2015). 
Evaluasi

Kerasionalan

Penggunaan Obat DM tipe-2

Pada Pasien Rawat Inap di

Rumah Sakit Bakti Wiratama

Semarang Pada Tahun 2006.

Jurnal Ilmu Farmasi dan

Farmasi Klinik, 4(1).

Atkinson A, Abernethy DR, Daniels CE, Dedrick RL, Markey SP.2007.

Principles of Clinical

Pharmacology Second

Edition.USA: Elsevier Inc.

p. 230 .

Badan Penelitian dan Pengembangan Kesehatan Departemen

Kesehatan, Republik Indonesia. 2013. Riset Kesehatan Dasar (RISKESDAS) Laporan asional 2012. Jakarta : Kementerian Kesehatan RI.

Corwin EJ, 2015. Buku Saku Patofisiologis. Subekti NB, penerjemah; Yudha EK, Wahyuningsih $E$, Yulianti $D$, Karyuni PE, editor, Jakarta : EGC, Terjemahan dari: Handbook of Pathofisiology.

Darmojo RB, Mariono, HH (2015). Geriatri (Ilmu Kesehatan Usia Lanjut). Edisi ke-3. Jakarta: Balai Penerbit FKUI.

[Depkes RI]. 2005. Pedoman Pembinaan Kesehatan Usia Lanjut Bagi Petugas Kesehatan. Jakarta : Depkes RI.

[Depkes RI].2005. Pharmaceutical Care Untuk penyakit Diabetes melitus.Direktorat Bina Farmasi Komunitas dan Klinik Direktorat Jendral Bina Kefarmasian dan Alat Kesehatan Departemen Kesehatan Republik Indonesia. Jakarta

[Depkes RI]. 2015. Pedoman Pembinaan Kesehatan Jiwa Usia Lanjut bagi Petugas Kesehatan. Jakarta: Depkes RI.

[Depkes RI].2018. Daftar Obat Esensial Nasional 2008. Direktorat
Jendral Bina Kefarmasian dan Alat Kesehatan. Jakarta : Departemen Kesehatan Republik Indonesia.

Dipiro.JT., 2017, Pharmacoterapy Handbook 7 edition, Mc Graw Hill, NewYork.

Gibney, Michael J, 2015. Gizi Kesehatan Masyarakat. Jakarta : EGC, 407-418.

Guyton, Arthur C, John E. Hall. 1997. Buku Ajar Fisiologi Kedokteran 9 ed.Jakarta: EGC

Handini, Y.P. 2015. Kejadian ulkus diabetes pada penderita diabetes melitus tipe 2 dengan atau tanpa dislipidemia. [skipsi]. Semarang: Medical Faculty of Diponegoro University

Hikmat P. 2015, Komplikasi kronik dan penyakit penyerta pada diabetes [Skripsi]. Bandung: Division on Endocronology and Metabolism. Departement of Internal Medicine. Padjajaran University Medical School. Hasan Sadikin Hospital.

Katzung, Bertram G. 2015. Farmakologi Dasar dan Klinik Edisi 10. Jakarta:EGC.

[Kemenkes RI]. Kementerian Kesehatan Republik Indonesia. Katalog dalam Terbitan Kementerian Kesehatan RI Indonesia: Pusat Data dan Informasi Profil Kesehatan Indonesia 2012, Jakarta: Kementerian Kesehatan RI; 2013.

Martono H, Pranarka K. 2016. Buku Ajar Boedhi-Darmojo Geriatri Edisi Keempat. Jakarta: Balai Penerbit FKUI. Hal.3-9.

Notoatmodjo, S. 2010. Metodologi Penelitian Kesehatan. Jakarta: Rineka Cipta.Price, Anderson S. 2005. Patofisiologi Konsep Klinis Proses-Proses Penyakit. Jakarta: EGC. 1259-1268. 
[PERKENI]. 2016. Konsesus Pengelolaan dan Pencegahan Diabetes Melitus Tipe2 di Indonesia 2006. Jakarta: PB. Perkeni.

[PERKENI]. 2016. Konsesus Pengelolaan dan Pencegahan Diabetes Melitus Tipe2 di Indonesia 2006. Jakarta: PB. Perkeni.

Potter AP, Perry AG. 2005. Buku Ajar Fundamental Keperawatan. Jakarta: EGC.

Probowati E. 2016. Faktor Resiko Gagal Ginjal Pada Diabetes Melitus.Universitas Diponegora

Fatimah 2015, Evaluasi Penggunaan Obat Antidiabetik Pada Pasien Dewasa Diabetes Mellitus Tipe 2 Di Instalasi Rawat Inap Rumah Sakit Umum Pusat DR. Sardjito Yogyakarta Tahun 2015, Skripsi, Fakultas Farmasi Universitas Islam Indonesia, Yogyakarta

[Riskesdas] Riset Kesehatan Dasar. 2013.Pedoman Pewancara Petugas Pengumpul Data. Jakarta: Badan Litbangkes Depkes RI.

Sugiyono. 2015. Metode Penelitian Kuantitatif, Kualitatif dan R \& D. Edisi ke-2. Bandung: Alfabeta Bandung. Kedokteran Universitas Indonesia.

Siwanto. S. 2015. Diabetes Melitus di Indonesia. Editor: Sudoyo A.W., Setiyohadi B., Alwi I., Simadibrata K.M., Setiati S., Buku Ajar Ilmu Penyakit Dalam Jilid III. Edisi IV. Hal 1852-1856. Balai Penerbit Fak. Kedokteran UI. Jakarta 